\title{
Thermal Boundary Layer in Flow due to an Exponentially Stretching Surface with an Exponentially Moving Free Stream
}

\author{
Krishnendu Bhattacharyya and G. C. Layek \\ Department of Mathematics, The University of Burdwan, Burdwan, West Bengal 713104, India \\ Correspondence should be addressed to Krishnendu Bhattacharyya; krish.math@yahoo.com
}

Received 24 January 2014; Revised 11 April 2014; Accepted 14 April 2014; Published 8 May 2014

Academic Editor: ShengKai Yu

Copyright ( $) 2014$ K. Bhattacharyya and G. C. Layek. This is an open access article distributed under the Creative Commons Attribution License, which permits unrestricted use, distribution, and reproduction in any medium, provided the original work is properly cited.

\begin{abstract}
A numerical investigation is made to study the thermal boundary layer for flow of incompressible Newtonian fluid over an exponentially stretching sheet with an exponentially moving free stream. The governing partial differential equations are transformed into self-similar ordinary differential equations using similarity transformations in exponential forms. Then those are solved numerically by shooting technique using Runge-Kutta method. The study reveals that the momentum boundary layer thickness for this flow is considerably smaller than the linear stagnation point flow past a linearly stretching sheet. The momentum and thermal boundary layer thicknesses reduce when the velocity ratio parameter increases. For the temperature distribution, in addition to the heat transfer from the sheet, the heat absorption at the sheet also occurs in certain situations and both heat transfer and absorption increase with the velocity ratio parameter and the Prandtl number. The temperature inside the boundary layer significantly decreases with higher values of velocity ratio parameter and the Prandtl number.
\end{abstract}

\section{Introduction}

The viscous fluid flow due to a stretching sheet is very significant problem in fluid dynamics due to its huge applications in many manufacturing processes, for example, the cooling of an infinite metallic plate in a cooling bath, the boundary layer along material handling conveyers, the aerodynamic extrusion of plastic sheets, the boundary layer along a liquid film in the condensation processes, hot rolling, paper production, metal spinning, glass-fiber production, and drawing of plastic films. The heat transfer from a stretching surface is of interest in polymer extrusion processes where the object, after passing through a die, enters the fluid for cooling below a certain temperature. During the processes, mechanical properties are greatly dependent upon the rate of cooling and the rate at which such objects are cooled has an important bearing on the properties of the final product. So, the quality of the final product depends on the rate of heat transfer from the stretching surface. The suitable choice of cooling liquid is very much crucial as it has a direct impact on rate of cooling of the surface.
Crane [1] first investigated the steady boundary layer flow of an incompressible viscous fluid over a linearly stretching plate and gave an exact similarity solution in closed analytical form. Crane's work was extended by many researchers such as P. S. Gupta and A. S. Gupta [2], Chen and Char [3], Pavlov [4], and Ali [5] considering the effects of heat and mass transfer and magnetic field under various physical conditions. Later, Ali [6] discussed the thermal boundary layer on a surface stretching with power law velocity. The mixed convection for the flow due to linearly stretching sheet with mass suction/injection was studied by Ali and Al-Yousef [7]. Ali [8] also investigated the buoyancy effects on the boundary layers induced by a rapidly stretching surface. Tsai et al. [9] discussed the effect of nonuniform heat source/sink on the flow and heat transfer from an unsteady stretching sheet through a quiescent fluid medium extending to infinity. In two important papers, Bhattacharyya and Layek $[10,11]$ explained the behaviour of chemically reactive solute distribution in MHD flow over a stretching sheet and in slip flow towards a vertical stretching sheet. Recently, Bhattacharyya $[12,13]$ presented effect of heat source/sink 
on the MHD boundary layer flow over steady and unsteady shrinking/stretching sheet and Bhattacharyya et al. [14] found the analytic solution of MHD flow of non-Newtonian Casson fluid flow induced due to stretching/shrinking sheet with wall mass transfer.

On the other hand, Hiemenz [15] first studied the steady flow in the neighbourhood of a stagnation point. Chiam [16] investigated a problem which is a combination of the works of Hiemenz [15] and Crane [1], that is, the linear stagnation point flow towards a linear stretching sheet when the stretching rate of the plate is equal to the strain rate of the stagnation point flow and he found no boundary layer structure near the plate. After few years, Mahapatra and Gupta [17] reinvestigated the same stagnation point flow towards a stretching sheet with different stretching and straining velocities and they found two kinds of boundary layers near the sheet depending on the ratio of the stretching and straining velocity rates. Wang [18] demonstrated the stagnation point flow towards a shrinking sheet. Furthermore, the behaviour of stagnation point flow over stretching/shrinking sheet under different physical aspects was discussed by many researchers [19-35].

In last few decades in almost all investigations of the flow over a stretching sheet, the flow occurs because of linear variation of stretching velocity of the flat sheet with the distance from the origin. So, the boundary layer flow induced by an exponentially stretching sheet is not studied much though it is very important and practical flow frequently appeared in many engineering processes. In 1999, Magyari and Keller [36] first consider the boundary layer flow due to an exponentially stretching sheet and he also studied the heat transfer in the flow taking exponentially varied wall temperature. After that, Elbashbeshy [37] numerically examined the flow and heat transfer over an exponentially stretching surface considering wall mass suction. Khan and Sanjayanand [38] investigated the flow of viscoelastic fluid and heat transfer over an exponentially stretching sheet with viscous dissipation effects. Partha et al. [39] presented a similarity solution for mixed convection flow past an exponentially stretching surface by taking into account the influence of viscous dissipation on the convective transport. Sanjayanand and Khan [40] discussed the effects of heat and mass transfer on the boundary layer flow of viscoelastic fluid taking $n$th order chemical reaction. Al-Odat et al. [41] investigated the effect magnetic field on thermal boundary layer on an exponentially stretching continuous surface with an exponential temperature distribution. Later, Sajid and Hayat [42] showed the influence of thermal radiation on the boundary layer flow past an exponentially stretching sheet and they reported series solutions for velocity and temperature using homotopy analysis method (HAM) and Bidin and Nazar [43] obtained a numerical solution of the same problem. Ishak [44] studied the MHD boundary layer flow over an exponentially stretching sheet in presence of thermal radiation. Mandal and Mukhopadhyay [45] analyzed the heat transfer in the flow due to an exponentially stretching porous sheet with surface heat flux embedded in a porous medium. Bhattacharyya [46] discussed the boundary layer flow and heat transfer past an exponentially shrinking sheet and Bhattacharyya and Pop [47] presented the effect of magnetic field on that flow. Recently, The MHD boundary layer nanofluid flow due to an exponentially stretching permeable sheet was demonstrated by Bhattacharyya and Layek [48].

Inspired by the above investigations, in the present paper, the thermal boundary layer in incompressible flow over an exponentially stretching sheet in an exponentially moving free stream is studied. The wall temperature distribution is taken variable in exponential form. Using similarity transformations, the governing partial differential equations are transformed into self-similar ordinary differential equations. Then the transformed equations are solved by standard shooting technique using fourth order Runge-Kutta method. The numerical computations are presented through some figures and the various characteristics of flow and heat transfer are thoroughly described. This type of flow is possible in reality in some special situations. The motive of the investigation is to study new type of flow dynamics and the heat transfer in the flow field.

\section{Analysis of Motion and Heat Transfer}

Consider the steady two-dimensional laminar boundary layer flow of a viscous incompressible fluid and heat transfer over an exponentially stretching sheet (of velocity $U_{w}$ ) with an exponentially moving free stream (of velocity $U_{\infty}$ ). The sheet coincides with the plane $y=0$ and the flow confined to $y>0$. The governing equations for the flow and the temperature are written in usual notation as

$$
\begin{gathered}
\frac{\partial u}{\partial x}+\frac{\partial v}{\partial y}=0 \\
u \frac{\partial u}{\partial x}+v \frac{\partial u}{\partial y}=U_{\infty} \frac{d U_{\infty}}{d x}+v \frac{\partial^{2} u}{\partial y^{2}} \\
u \frac{\partial T}{\partial x}+v \frac{\partial T}{\partial y}=\frac{\kappa}{\rho c_{p}} \frac{\partial^{2} T}{\partial y^{2}}
\end{gathered}
$$

where $u$ and $v$ are the velocity components in $x$ and $y$ directions, respectively, $U_{\infty}$ is the fluid velocity in free stream, $v(=\mu / \rho)$ is the kinematic fluid viscosity, $\rho$ is the fluid density, $\mu$ is the coefficient of fluid viscosity, $T$ is the temperature, $\kappa$ is the fluid thermal conductivity, and $c_{p}$ is the specific heat. The diagram of the physical problem is given in Figure 1.

The boundary conditions corresponding to the velocity components and the temperature are given by

$$
\begin{gathered}
u=U_{w}(x), \quad v=0 \quad \text { at } y=0 ; \\
u \longrightarrow U_{\infty}(x) \quad \text { as } y \longrightarrow \infty, \\
T=T_{w}=T_{\infty}+T_{0} \exp \left(\frac{\lambda x}{2 L}\right) \quad \text { at } y=0 ; \\
T \longrightarrow T_{\infty} \quad \text { as } y \longrightarrow \infty,
\end{gathered}
$$

where $T_{w}$ is the variable temperature of the sheet, $T_{\infty}$ is the free stream temperature assumed to be constant, $T_{0}$ is a constant which measures the rate of temperature increase 


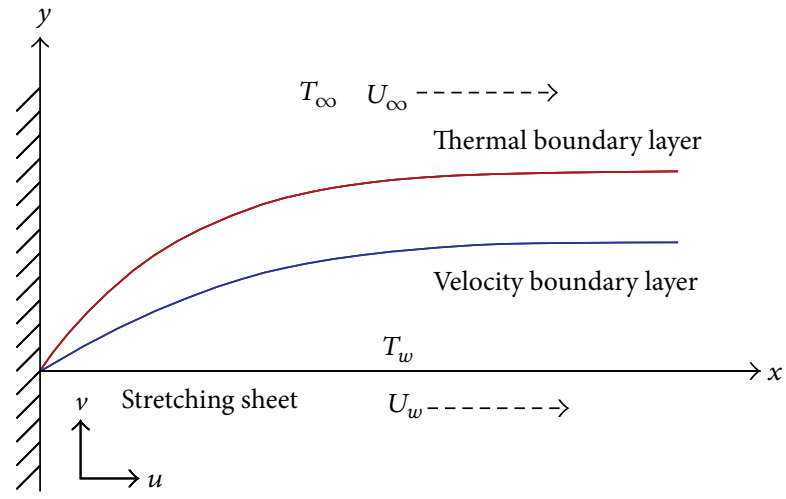

FIgURE 1: A diagram of the physical problem.

along the sheet, $L$ denotes the reference length, and $\lambda$ is a parameter which is physically very important in controlling the exponential increment of temperature along the sheet and it may have both positive and negative values. The stretching and free stream velocities $U_{w}$ and $U_{\infty}$ are, respectively, given by

$$
U_{w}(x)=c \exp \left(\frac{x}{L}\right), \quad U_{\infty}(x)=a \exp \left(\frac{x}{L}\right)
$$

where $c$ and $a$ are constants with $c>0$ and $a \geq 0$ (for without any free stream $a=0$ ).

Now, the stream function $\psi(x, y)$ is given by

$$
u=\frac{\partial \psi}{\partial y}, \quad v=-\frac{\partial \psi}{\partial x} .
$$

For relations in (7), the continuity equation (1) is identically satisfied and the momentum equation (2) and the temperature equation (3) are reduced to the following forms:

$$
\begin{gathered}
\frac{\partial \psi}{\partial y} \frac{\partial^{2} \psi}{\partial x \partial y}-\frac{\partial \psi}{\partial x} \frac{\partial^{2} \psi}{\partial y^{2}}=U_{\infty} \frac{d U_{\infty}}{d x}+v \frac{\partial^{3} \psi}{\partial y^{3}} \\
\frac{\partial \psi}{\partial y} \frac{\partial T}{\partial x}-\frac{\partial \psi}{\partial x} \frac{\partial T}{\partial y}=\frac{\kappa}{\rho c_{p}} \frac{\partial^{2} T}{\partial y^{2}}
\end{gathered}
$$

The boundary conditions in (4) for the flow become

$$
\begin{gathered}
\frac{\partial \psi}{\partial y}=U_{w}(x), \quad \frac{\partial \psi}{\partial x}=0 \quad \text { at } y=0 \\
\frac{\partial \psi}{\partial y} \longrightarrow U_{\infty}(x) \quad \text { as } y \longrightarrow \infty
\end{gathered}
$$

Next, the dimensionless variables for $\psi$ and $T$ are introduced as

$$
\begin{aligned}
& \psi=\sqrt{2 v L c} f(\eta) \exp \left(\frac{x}{2 L}\right), \\
& T=T_{\infty}+\left(T_{w}-T_{\infty}\right) \theta(\eta),
\end{aligned}
$$

where $\eta$ is the similarity variable and is defined as $\eta=$ $y \sqrt{c / 2 v L} \exp (x / 2 L)$.
Using (10), finally the following nonlinear self-similar equations are obtained:

$$
\begin{gathered}
f^{\prime \prime \prime}+f f^{\prime \prime}-2 f^{\prime 2}+2\left(\frac{a}{c}\right)^{2}=0, \\
\theta^{\prime \prime}+\operatorname{Pr}\left(f \theta^{\prime}-\lambda f^{\prime} \theta\right)=0,
\end{gathered}
$$

where $a / c$ is the velocity ratio parameter and $\operatorname{Pr}=\mu c_{p} / \kappa$ is the Prandtl number.

The boundary conditions in (9) and (5) reduce to the following forms:

$$
\begin{gathered}
f(\eta)=0, \quad f^{\prime}(\eta)=1 \quad \text { at } \eta=0 ; \\
f^{\prime}(\eta) \longrightarrow \frac{a}{c} \quad \text { as } \eta \longrightarrow \infty, \\
\theta(\eta)=1 \quad \text { at } \eta=0 ; \quad \theta(\eta) \longrightarrow 0 \quad \text { as } \eta \longrightarrow \infty .
\end{gathered}
$$

When $c=a$, (11) gives closed form analytical solution $f(\eta)=$ $\eta$ which is the same as the linear stagnation-point flow over a stretching sheet with velocity varied linearly to the distance from the origin.

The physical quantities of interest in this problem are the local skin-friction coefficient and the local Nusselt number. The dimensionless local skin-friction coefficient is expressed as

$$
C_{f x}=\frac{\left.\tau_{w}\right|_{y=0}}{\rho U_{w}^{2}},
$$

where $\tau_{w}$ is the shear stress at the wall and is given by $\tau_{w}=$ $\mu[\partial u / \partial y]_{y=0}$. So,

$$
\sqrt{2 \operatorname{Re}} C_{f x}=f^{\prime \prime}(0),
$$

where $\operatorname{Re}=U_{w} L / v$ is the Reynolds number.

The local Nusselt number can be written as

$$
\mathrm{Nu}_{x}=-\left.\frac{x}{T_{w}-T_{\infty}} \frac{\partial T}{\partial y}\right|_{y=0} .
$$

So,

$$
\frac{\mathrm{Nu}_{x}}{\sqrt{\mathrm{Re}_{x}}}=-\sqrt{\frac{x}{2 L}} \theta^{\prime}(0),
$$

where $\operatorname{Re}_{x}=U_{w} x / v$ is the local Reynolds number.

\section{Numerical Method for Solution}

The nonlinear coupled differential equations (11) and (12) along with the boundary conditions (13) form a two point boundary value problem (BVP) and is solved using shooting method, by converting it into an initial value problem (IVP). In this method, it is necessary to choose a suitable finite value of $\eta \rightarrow \infty$, say $\eta_{\infty}$. The following first-order system is set:

$$
\begin{gathered}
f^{\prime}=p, \quad p^{\prime}=q, \quad q^{\prime}=2 p^{2}-f q-2\left(\frac{a}{c}\right)^{2}, \\
\theta^{\prime}=z, \quad z^{\prime}=-\operatorname{Pr}(f z-\lambda p \theta)
\end{gathered}
$$




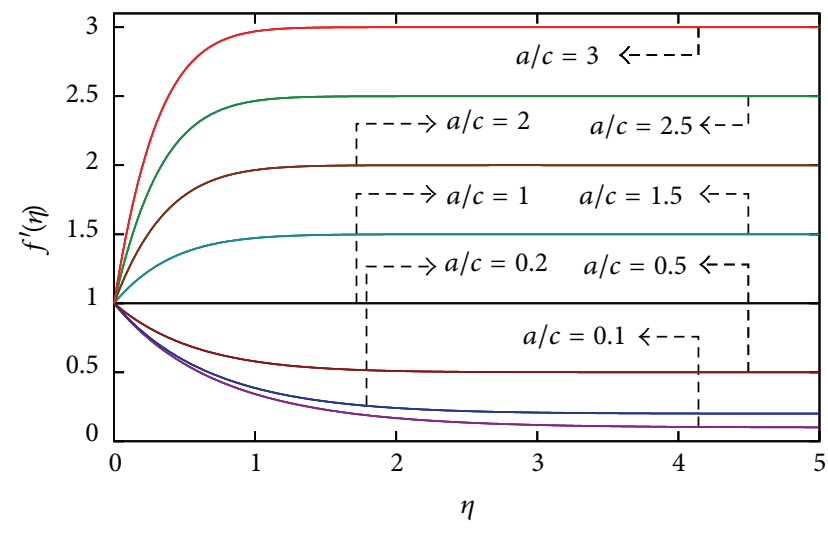

FIGURE 2: Velocity profiles $f^{\prime}(\eta)$ for various values of $a / c$.

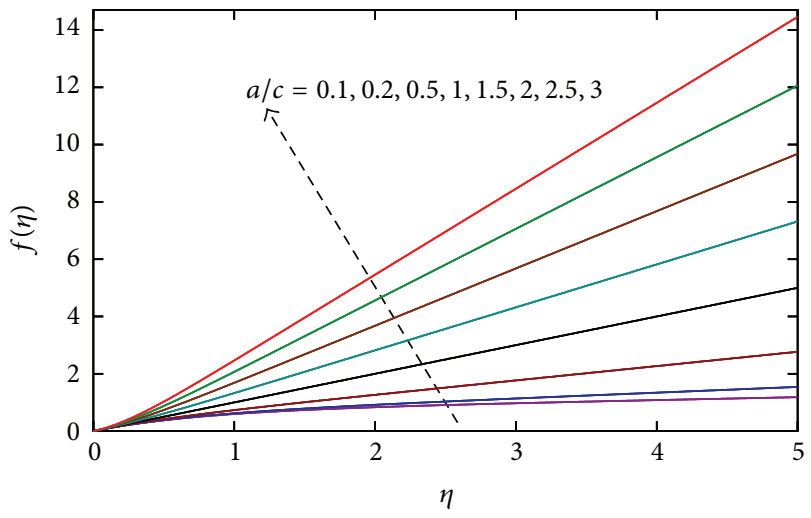

Figure 3: The variations of $f(\eta)$ for various values of $a / c$.

with the boundary conditions

$$
f(0)=0, \quad p(0)=1, \quad \theta(0)=1 .
$$

To solve (18) with (19) as an IVP, the values for $q(0)$, that is, $f^{\prime \prime}(0)$, and $z(0)$, that is, $\theta^{\prime}(0)$, are needed but no such values are given. The initial guess values for $f^{\prime \prime}(0)$ and $\theta^{\prime}(0)$ are chosen and the fourth-order Runge-Kutta method is applied to obtain the solution. The calculated values of $f^{\prime}(\eta)$ and $\theta(\eta)$ at $\eta_{\infty}(=25)$ are compared with the given boundary conditions $f^{\prime}\left(\eta_{\infty}\right)=a / c$ and $\theta\left(\eta_{\infty}\right)=0$ and adjust values of $f^{\prime \prime}(0)$ and $\theta^{\prime}(0)$ using "secant method" to give better approximation for the solution. The step size is taken as $\Delta \eta=$ 0.01 . The process is repeated until we get the results correct up to the desired accuracy of $10^{-6}$ level.

\section{Results and Discussion}

The numerical computations have been carried out for various values of the physical parameters involved in the equations, namely, the velocity ratio parameter $a / c$, the Prandtl number Pr, and the parameter $\lambda$. For illustration of the results, computed values are plotted through graphs and the physical explanations are rendered for all cases.

To ensure the accuracy of the numerical scheme, we compare the values of $f^{\prime \prime}(0)$ and $f(\infty)$ with the published

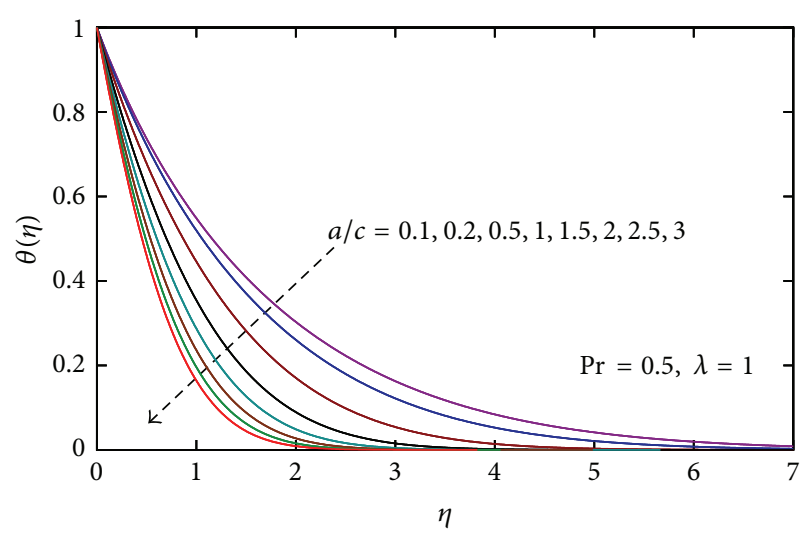

FIGURE 4: Temperature profiles $\theta(\eta)$ for various values of $a / c$.

TABLE 1: The values of $f^{\prime \prime}(0)$ and $f(\infty)$ for $a / c=0$.

\begin{tabular}{lcc}
\hline & Magyari and Keller [36] & Present study \\
\hline$-f^{\prime \prime}(0)$ & 1.281808 & 1.2818084 \\
$f(\infty)$ & 0.905639 & 0.9056433 \\
\hline
\end{tabular}

data by Magyari and Keller [36] in Table 1 without any exponential free stream, $U_{\infty}=0$ that is $a / c=0(a=0)$ and those are found in excellent agreement. Thus, we are feeling confident that the presented results are accurate.

As similar to that of stagnation point flow with linear straining velocity towards a linearly stretching sheet, in the boundary layer flow with exponentially varied free stream velocity over exponentially stretching sheet two different kinds of boundary layer structures have formed near the sheet depending upon the ratio of two constants relating to the stretching and free stream velocities, that is, on the velocity ratio parameter $a / c$, for $a / c>1$ and $a / c<1$. Also, it is important to note that for $a / c=1$ no velocity boundary layer is formed near the sheet. The velocity profiles for various values of $a / c$ are depicted in Figure 2. Also, the variations of $f(\eta)$ and the dimensionless temperature for different values of $a / c$ are plotted in Figures 3 and 4 . It is observed that $f(\eta)$ increases with increasing values of $a / c$ and the temperature at a point decreases with $a / c$.

The momentum and thermal boundary layer thicknesses are denoted by $\delta$ and $\delta_{T}$, respectively, and are described by the equations $\delta=\eta_{\delta} \sqrt{2 v L / c} \exp (-x / 2 L)$ and $\delta_{T}=$ $\eta_{\delta T} \sqrt{2 v L / c} \exp (-x / 2 L)$. The dimensionless boundary layer thicknesses $\eta_{\delta}$ and $\eta_{\delta T}$ are defined as the values of $\eta$ (nondimensional distance from the surface) at which the difference of dimensionless velocity $f^{\prime}(\eta)$ and the parameter $a / c$ has been reduced to 0.001 and the dimensionless temperature $\theta(\eta)$ has been decayed to 0.001 , respectively. Both boundary layer thicknesses are very vital in practical and theoretical standpoints. The values $\eta_{\delta}$ and $\eta_{\delta T}$ are given in Table 2 for several values of $a / c$. From the table, it is seen that the momentum boundary layer thickness decreases when $a / c$ increases (both for $a / c>1$ and $a / c<1$ ). But, it is worth noting that the momentum boundary layer thickness is considerably thinner than that of the boundary layer of linear 
TABLE 2: Values of $\eta_{\delta}$ and $\eta_{\delta T}$ for several values of $a / c$ with $\operatorname{Pr}=0.5$ and $\lambda=1$.

\begin{tabular}{lcccccccc}
\hline & $a / c$ & 0.1 & 0.2 & 0.5 & 1.5 & 2.0 & 2.5 & 3.0 \\
\hline Mahapatra and Gupta [17] & $\eta_{\delta}$ & 6.96 & 5.91 & 4.36 & - & 2.62 & - & 2.30 \\
\hline \multirow{2}{*}{ Present study } & $\eta_{\delta}$ & 5.04 & 4.17 & 2.91 & 1.87 & 1.79 & 1.68 & 1.59 \\
& $\eta_{\delta T}$ & 8.97 & 7.78 & 5.63 & 3.54 & 3.11 & 2.80 & 2.57 \\
\hline
\end{tabular}

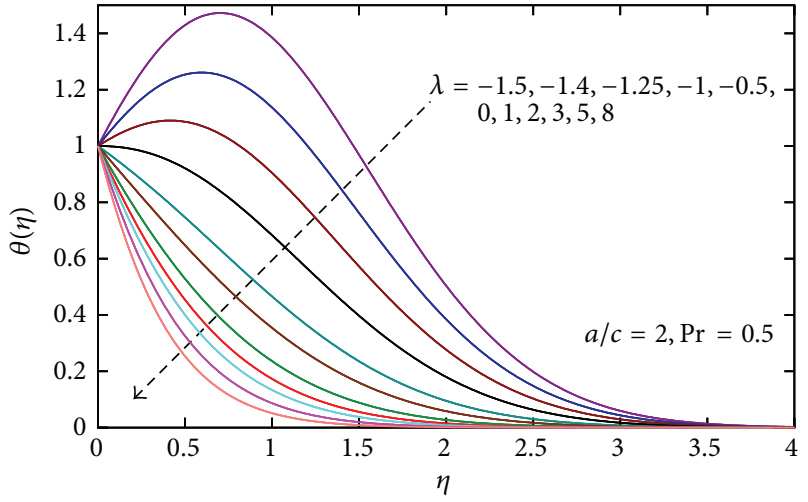

Figure 5: Temperature profiles $\theta(\eta)$ for various values of $\lambda$ with $a / c=2$.

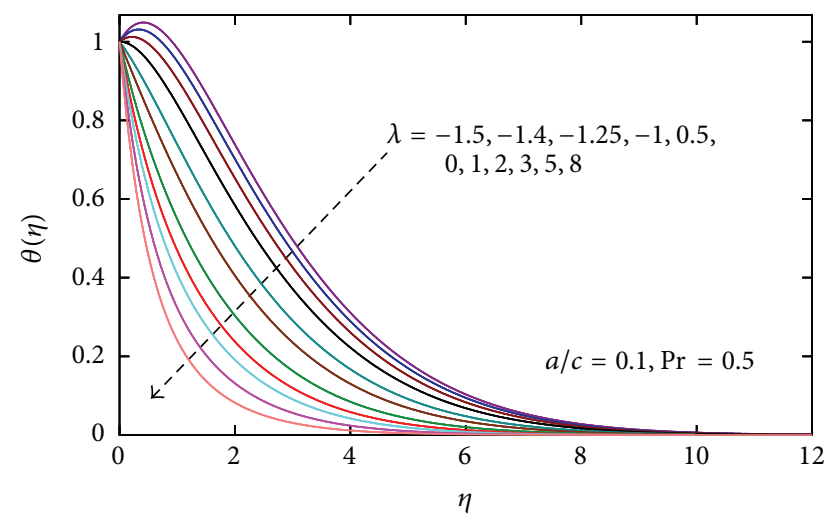

FIgURE 6: Temperature profiles $\theta(\eta)$ for various values of $\lambda$ with $a / c=0.1$.

stagnation point flow over a linearly stretching sheet which is obtained by Mahapatra and Gupta [17]. In exponential flow past an exponentially stretching sheet though the flow dynamics is similar to that of linear stagnation point flow, the momentum boundary layer thickness is smaller and it is physically important. Due to the fact that larger velocities of the free stream and the surface stretching make the nonzero viscosity layer thinner, it makes boundary layer thickness thinner. Similar to the velocity field, the thermal boundary layer thickness also decreases with increase of $a / c$.

The effect of the parameter $\lambda$ on the temperature distribution is very significant because the increase of wall temperature along the sheet depends upon $\lambda$. For various values of $\lambda$, the dimensionless temperature profiles $\theta(\eta)$ are presented in Figures 5 and 6 for $a / c=2$ and $a / c=0.1$, respectively. In both the cases, the figures exhibit the overshoot of temperature profiles for some negative values of $\lambda$. Hence, when the

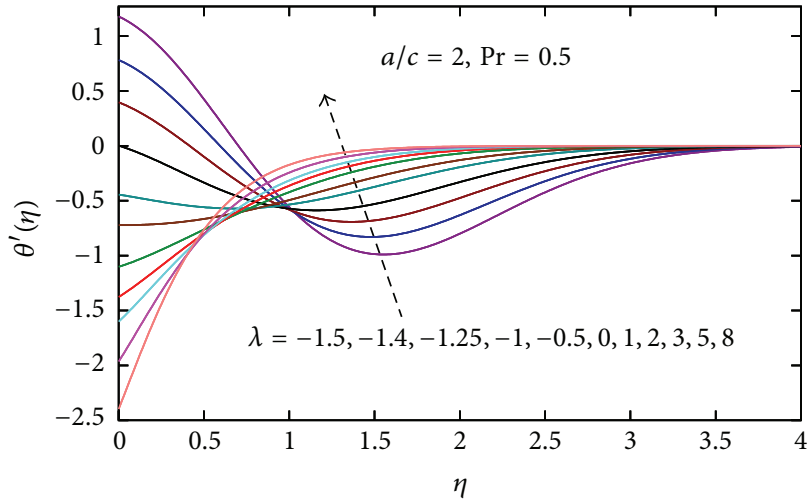

FIGURE 7: Temperature gradient profiles $\theta^{\prime}(\eta)$ for various values of $\lambda$ with $a / c=2$.

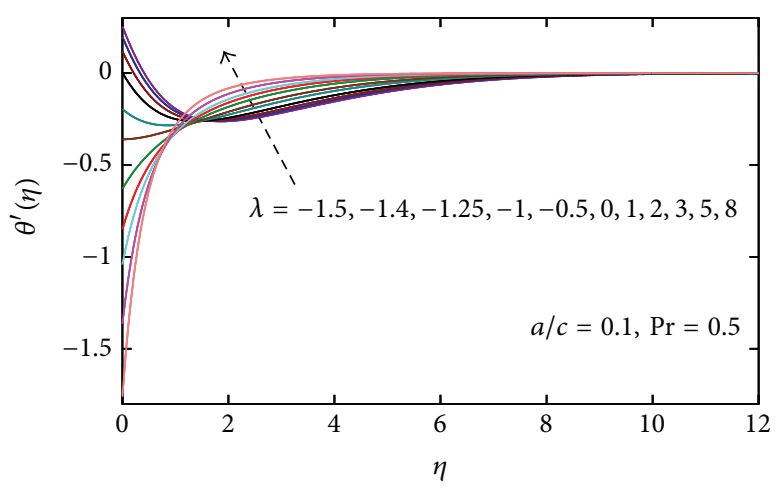

FIGURE 8: Temperature gradient profiles $\theta^{\prime}(\eta)$ for various values of $\lambda$ with $a / c=0.1$.

wall temperature in inverse exponential forms, the thermal overshoot occurs. Also, it is noticed that the temperatures at particular point and the thermal boundary layer thickness decrease with increase of $\lambda$. Furthermore, it is very important to note that the overshoot pick is of higher length when free stream velocity is large compared to the stretching velocity $(a / c=2)$. The dimensionless temperature gradient profiles $\theta^{\prime}(\eta)$ for different $\lambda$ are depicted in Figures 7 and 8 for $a / c=2$ and $a / c=0.1$, respectively. From these two figures, it is clearly seen that the temperature gradient at the sheet is positive for some values of $\lambda$ and negative for some other values of $\lambda$. So, heat transfer from the sheet and heat absorption at the sheet occur depending on the values of $\lambda$ for both values of $a / c$. Because of inverse exponential distribution of surface temperature $(\lambda>0)$, the heat absorption is found in the thermal boundary layer. Thus the parameter $\lambda$ related to wall temperature plays a vital role in controlling the cooling 


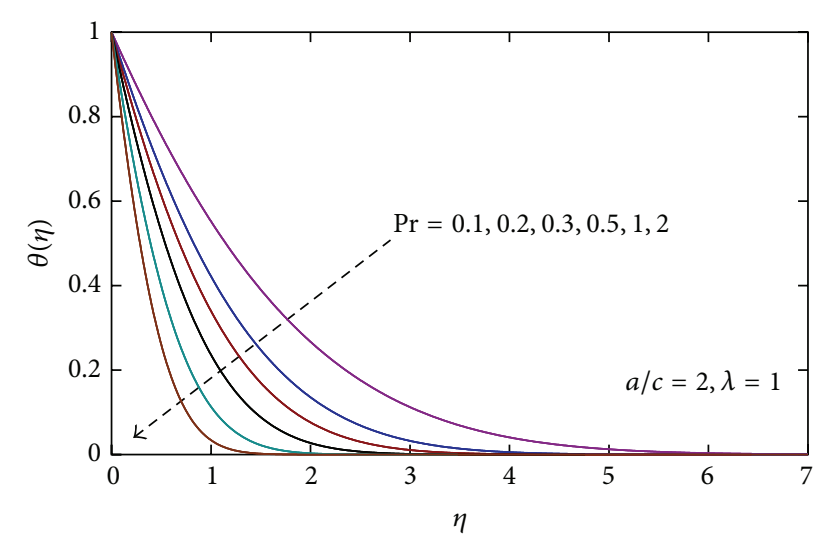

FIgURE 9: Temperature profiles $\theta(\eta)$ for various values of $\operatorname{Pr}$ with $a / c=2$ and $\lambda=1$.

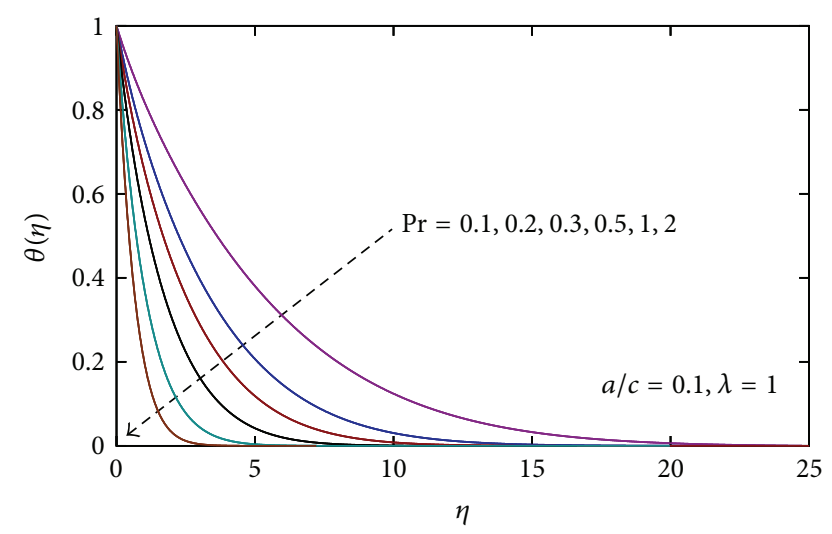

FIgURE 10: Temperature profiles $\theta(\eta)$ for various values of $\operatorname{Pr}$ with $a / c=0.1$ and $\lambda=1$.

process of the surface and consequently it has a great impact on the quality of the manufactured products.

The temperature profiles for various values of Prandtl number Pr are demonstrated in Figures 9-12 with $a / c=2$, 0.1 and $\lambda=1,-1.5$. In Figures 9 and 10 , for $\lambda=1$, it is observed that the temperature at a fixed point decreases with $\operatorname{Pr}$ for both values of $a / c$. Accordingly, the thermal boundary layer thickness decreases with increasing values of $\mathrm{Pr}$ and the heat transfers from the sheet to the adjacent fluid. But, when $\lambda=-1.5$ (Figures 11 and 12), the temperature overshoot is observed; that is, the sheet absorbs the heat and interestingly for both values of $a / c$ the height of the overshoot pick increases with $\mathrm{Pr}$, so the heat absorption at the sheet also increases. However, similar to the linear case, in this situation the thermal boundary layer thickness decreases with increasing values of Pr. For increase of Prandtl number, the fluid thermal conductivity reduces and consequently the thermal boundary layer thickness becomes thinner.

The values of $f^{\prime \prime}(0)$ related to local skin-friction coefficient and $-\theta^{\prime}(0)$ related to local Nusselt number are plotted in Figures $13-15$ for various values of $a / c, \lambda$ and Pr. The value of $f^{\prime \prime}(0)$ increases with velocity ratio parameter $a / c$. Also, the value of $-\theta^{\prime}(0)$ increases with $\lambda$. Moreover, for the larger

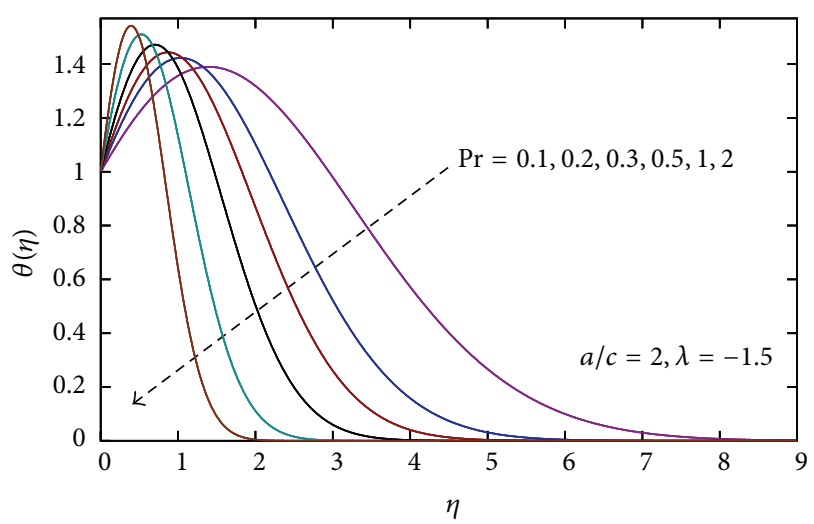

FIgURE 11: Temperature profiles $\theta(\eta)$ for various values of $\operatorname{Pr}$ with $a / c=2$ and $\lambda=-1.5$.

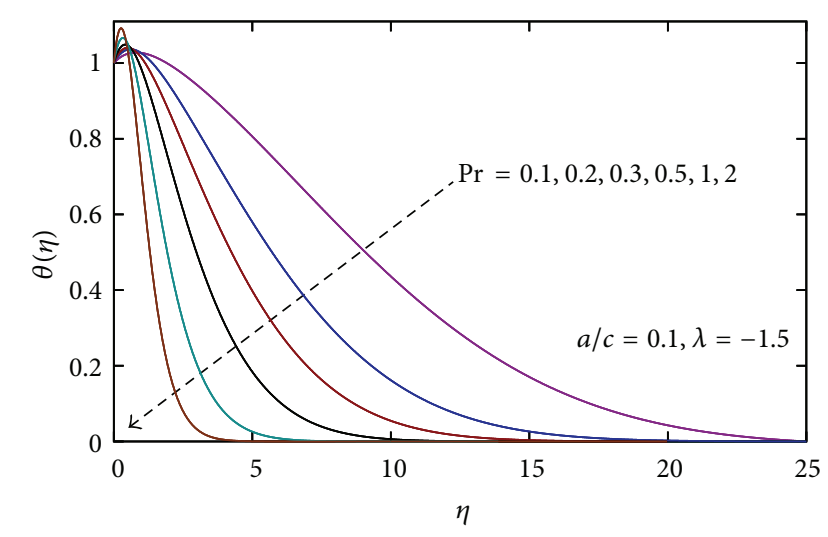

FigURE 12: Temperature profiles $\theta(\eta)$ for various values of $\operatorname{Pr}$ with $a / c=0.1$ and $\lambda=-1.5$.

negative values of $\lambda$, the heat absorption $\left[-\theta^{\prime}(0)<0\right]$ at the surface is found. With the increase of $a / c$ and $\operatorname{Pr}$, the heat transfer enhances and also heat absorption becomes larger (Figures 14 and 15).

\section{Concluding Remarks}

The momentum and heat transfer characteristics of the laminar boundary layer flow induced by an exponentially stretching sheet in an exponentially moving free stream are investigated. The transformed governing equations are solved by shooting technique using Runge-Kutta method. The findings of this study can be summarized as follows.

(a) The momentum boundary layer thickness for this flow is significantly smaller than that of the linear stagnation point flow past a linearly stretching sheet.

(b) The momentum and thermal boundary layer thicknesses decrease with increase of velocity ratio parameter $a / c$.

(c) For positive values of $\lambda$ and smaller negative values heat transfers from surface to the ambient fluid and importantly for greater negative value of $\lambda$ heat 

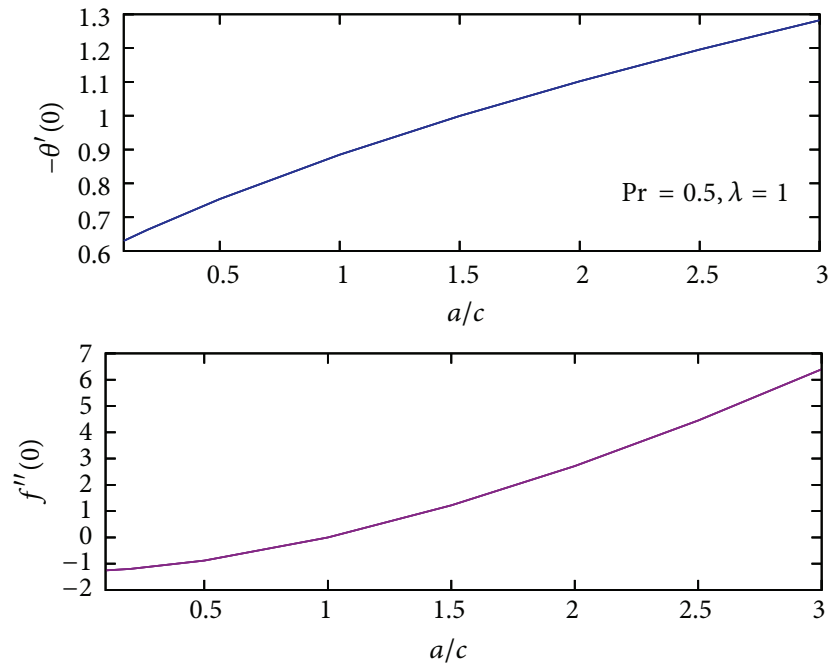

FIgURE 13: Values of $f^{\prime \prime}(0)$ and $-\theta^{\prime}(0)$ for various values of $a / c$.

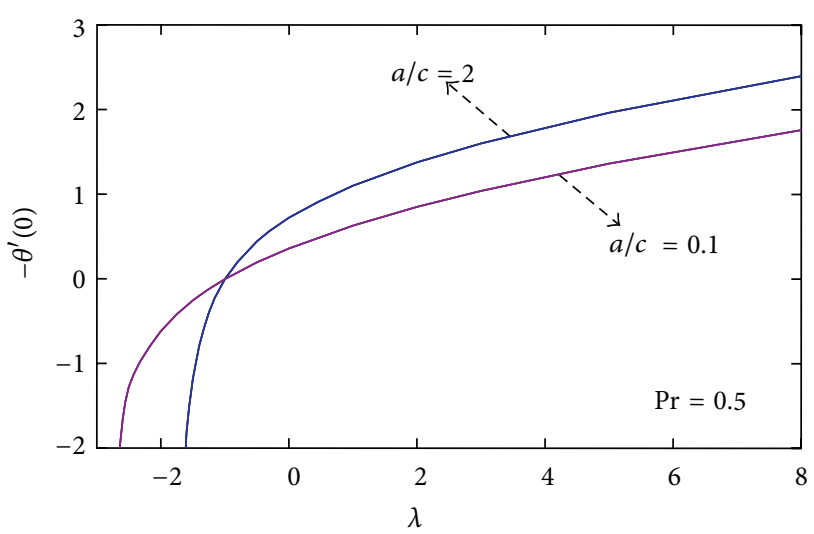

Figure 14: Values of $-\theta^{\prime}(0)$ versus $\lambda$ for various values of $a / c$ with $\operatorname{Pr}=0.5$.
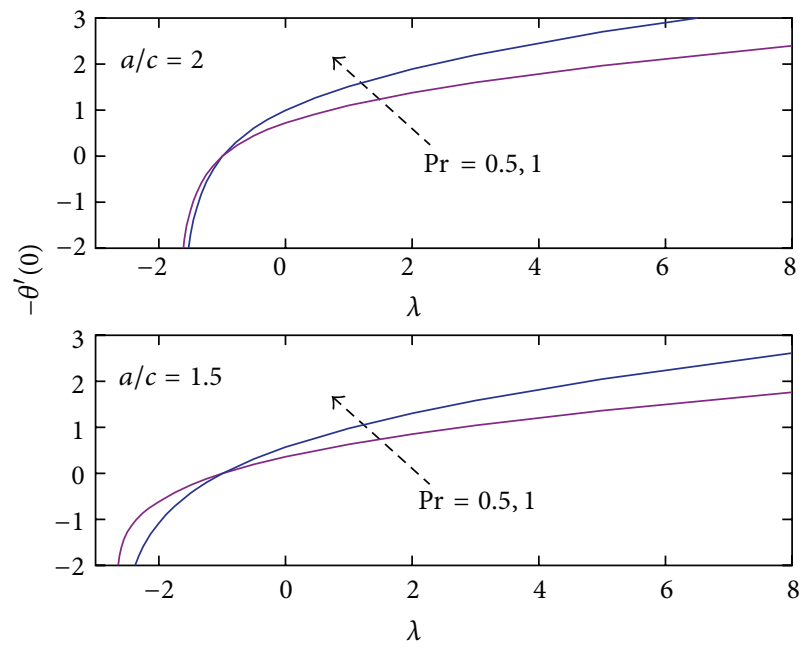

Figure 15: Values of $-\theta^{\prime}(0)$ versus $\lambda$ for various values of $a / c$ and $\operatorname{Pr}$. transfers from the ambient fluid to the surface, the heat absorption occurs.

(d) Temperature and thermal boundary layer thicknesses decrease with $\lambda$, a parameter associated with wall temperature.

(e) The heat transfer from the sheet and the heat absorption at the sheet are enhanced with the increase in both velocity ratio parameter and Prandtl number.

\section{Nomenclature}

a: Constant related to free stream velocity

$c$ : Constant related to stretching velocity

$a / c$ : Velocity ratio parameter

$c_{p}:$ Specific heat

$f$ : Dimensionless stream function

L: $\quad$ Reference length

Pr: Prandtl number

T: $\quad$ Temperature

$T_{w}$ : Variable temperature of the sheet

$T_{\infty}$ : Free stream temperature

$u$ : velocity component in $x$ direction

$v$ : Velocity component in $y$ direction

$U_{w}$ : Stretching velocity

$U_{\infty}$ : Free stream velocity

$\eta$ : Similarity variable

$\kappa$ : $\quad$ Fluid thermal conductivity

$\lambda$ : Parameter

$\mu$ : Coefficient of fluid viscosity

$v$ : Kinematic viscosity of fluid

$\rho: \quad$ Density of fluid

$\psi: \quad$ Stream function

$\theta$ : Dimensionless temperature.

\section{Conflict of Interests}

The authors declare that there is no conflict of interests regarding the publication of this paper.

\section{Acknowledgments}

One of the authors, K. Bhattacharyya gratefully acknowledges the financial support of National Board for Higher Mathematics (NBHM), Department of Atomic Energy, Government of India, for pursuing this work. The authors also express his sincere thanks to the esteemed referees for their constructive suggestions.

\section{References}

[1] L. J. Crane, "Flow past a stretching plate," Zeitschrift für Angewandte Mathematik und Physik, vol. 21, no. 4, pp. 645-647, 1970.

[2] P. S. Gupta and A. S. Gupta, "Heat and mass transfer on a stretching sheet with suction and blowing," The Canadian Journal of Chemical Engineering, vol. 55, no. 6, pp. 744-746, 1977. 
[3] C.-K. Chen and M.-I. Char, "Heat transfer of a continuous, stretching surface with suction or blowing," Journal of Mathematical Analysis and Applications, vol. 135, no. 2, pp. 568-580, 1988.

[4] K. B. Pavlov, "Magnetohydrodynamic flow of an incompressible viscous fluid caused by the deformation of a plane surface," Magnitnaya Gidrodinamika, vol. 10, pp. 146-148, 1974.

[5] M. E. Ali, "Heat transfer characteristics of a continuous stretching surface," Heat and Mass Transfer, vol. 29, no. 4, pp. 227-234, 1994.

[6] M. E. Ali, "On thermal boundary layer on a power-law stretched surface with suction or injection," International Journal of Heat and Fluid Flow, vol. 16, no. 4, pp. 280-290, 1995.

[7] M. Ali and F. Al-Yousef, "Laminar mixed convection boundary layers induced by a linearly stretching permeable surface," International Journal of Heat and Mass Transfer, vol. 45, no. 21, pp. 4241-4250, 2002.

[8] M.E. Ali, "The buoyancy effects on the boundary layers induced by continuous surfaces stretched with rapidly decreasing velocities," Heat and Mass Transfer, vol. 40, no. 3-4, pp. 285-291, 2004.

[9] R. Tsai, K. H. Huang, and J. S. Huang, "Flow and heat transfer over an unsteady stretching surface with non-uniform heat source," International Communications in Heat and Mass Transfer, vol. 35, no. 10, pp. 1340-1343, 2008.

[10] K. Bhattacharyya and G. C. Layek, "Chemically reactive solute distribution in MHD boundary layer flow over a permeable stretching sheet with suction or blowing," Chemical Engineering Communications, vol. 197, no. 12, pp. 1527-1540, 2010.

[11] K. Bhattacharyya and G. C. Layek, "Slip effect on diffusion of chemically reactive species in boundary layer flow over a vertical stretching sheet with suction or blowing," Chemical Engineering Communications, vol. 198, no. 11, pp. 1354-1365, 2011.

[12] K. Bhattacharyya, "Effects of heat source/sink on mhd flow and heat transfer over a shrinking sheet with mass suction," Chemical Engineering Research Bulletin, vol. 15, no. 1, pp. 12-17, 2011.

[13] K. Bhattacharyya, "Effects of radiation and heat source/sink on unsteady MHD boundary layer flow and heat transfer over a shrinking sheet with suction/injection," Frontiers of Chemical Engineering in China, vol. 5, no. 3, pp. 376-384, 2011.

[14] K. Bhattacharyya, T. Hayat, and A. Alsaedi, "Analytic solution for magnetohydrodynamic boundary layer flow of Casson fluid over a stretching/shrinking sheet with wall mass transfer," Chinese Physics B, vol. 22, no. 2, Article ID 024702, 2013.

[15] K. Hiemenz, "Die Grenzschicht an einem in den gleichformingen Flussigkeits-strom einge-tauchten graden Kreiszylinder," Dinglers Polytechnic Journal, vol. 326, pp. 321-324, 1911.

[16] T. C. Chiam, "Stagnation-point flow towards a stretching plate," Journal of the Physical Society of Japan, vol. 63, no. 6, pp. 24432444, 1994.

[17] T. R. Mahapatra and A. S. Gupta, "Magnetohydrodynamic stagnation-point flow towards a stretching sheet," Acta Mechanica, vol. 152, no. 1-4, pp. 191-196, 2001.

[18] C. Y. Wang, "Stagnation flow towards a shrinking sheet," International Journal of Non-Linear Mechanics, vol. 43, no. 5, pp. 377-382, 2008.

[19] T. R. Mahapatra and A. S. Gupta, "Heat transfer in stagnationpoint flow towards a stretching sheet," Heat and Mass Transfer, vol. 38 , no. 6 , pp. 517-521, 2002.
[20] R. Nazar, N. Amin, D. Filip, and I. Pop, "Stagnation point flow of a micropolar fluid towards a stretching sheet," International Journal of Non-Linear Mechanics, vol. 39, no. 7, pp. 1227-1235, 2004.

[21] A. Ishak, R. Nazar, and I. Pop, "Mixed convection boundary layers in the stagnation-point flow toward a stretching vertical sheet," Meccanica, vol. 41, no. 5, pp. 509-518, 2006.

[22] G. C. Layek, S. Mukhopadhyay, and S. A. Samad, "Heat and mass transfer analysis for boundary layer stagnationpoint flow towards a heated porous stretching sheet with heat absorption/generation and suction/blowing," International Communications in Heat and Mass Transfer, vol. 34, no. 3, pp. 347-356, 2007.

[23] T. Hayat, T. Javed, and Z. Abbas, "MHD flow of a micropolar fluid near a stagnation-point towards a non-linear stretching surface," Nonlinear Analysis: Real World Applications, vol. 10, no. 3, pp. 1514-1526, 2009.

[24] K. Bhattacharyya, S. Mukhopadhyay, and G. C. Layek, "Slip effects on an unsteady boundary layer stagnation-point flow and heat transfer towards a stretching sheet," Chinese Physics Letters, vol. 28, no. 9, Article ID 094702, 2011.

[25] A. Ishak, Y. Y. Lok, and I. Pop, "Stagnation-point flow over a shrinking sheet in a micropolar fluid," Chemical Engineering Communications, vol. 197, no. 11, pp. 1417-1427, 2010.

[26] K. Bhattacharyya and G. C. Layek, "Effects of suction/blowing on steady boundary layer stagnation-point flow and heat transfer towards a shrinking sheet with thermal radiation," International Journal of Heat and Mass Transfer, vol. 54, no. 1-3, pp. 302-307, 2011.

[27] K. Bhattacharyya, S. Mukhopadhyay, and G. C. Layek, "Slip effects on boundary layer stagnation-point flow and heat transfer towards a shrinking sheet," International Journal of Heat and Mass Transfer, vol. 54, no. 1-3, pp. 308-313, 2011.

[28] T. R. Mahapatra, S. K. Nandy, and A. S. Gupta, "Momentum and heat transfer in MHD stagnation-point flow over a shrinking sheet," Journal of Applied Mechanics, Transactions ASME, vol. 78, no. 2, Article ID 021015, 2011.

[29] K. Bhattacharyya and K. Vajravelu, "Stagnation-point flow and heat transfer over an exponentially shrinking sheet," Communications in Nonlinear Science and Numerical Simulation, vol. 17, no. 7, pp. 2728-2734, 2012.

[30] P. D. Weidman and M. E. Ali, "Aligned and nonaligned radial stagnation flow on a stretching cylinder," European Journal of Mechanics B: Fluids, vol. 30, no. 1, pp. 120-128, 2011.

[31] K. Bhattacharyya, "Dual solutions in boundary layer stagnation-point flow and mass transfer with chemical reaction past a stretching/shrinking sheet," International Communications in Heat and Mass Transfer, vol. 38, no. 7, pp. 917-922, 2011.

[32] K. Bhattacharyya, "Dual solutions in unsteady stagnation-point flow over a shrinking sheet," Chinese Physics Letters, vol. 28, no. 8, Article ID 084702, 2011.

[33] K. Bhattacharyya, G. Arif, and W. A. Pramanik, "MHD boundary layer stagnation-point flow and mass transfer over a permeable shrinking sheet with suction/blowing and chemical reaction," Acta Technica, vol. 57, pp. 1-15, 2012.

[34] K. Bhattacharyya, S. Mukhopadhyay, and G. C. Layek, "Reactive solute transfer in magnetohydrodynamic boundary layer stagnation-point flow over a stretching sheet with suction/blowing," Chemical Engineering Communications, vol. 199, no. 3, pp. 368-383, 2012. 
[35] K. Bhattacharyya, "Heat transfer in unsteady boundary layer stagnation-point flow towards a shrinking sheet," Ain Shams Engineering Journal, vol. 4, no. 2, pp. 259-264, 2013.

[36] E. Magyari and B. Keller, "Heat and mass transfer in the boundary layers on an exponentially stretching continuous surface," Journal of Physics D: Applied Physics, vol. 32, no. 5, pp. 577-585, 1999.

[37] E. M. A. Elbashbeshy, "Heat transfer over an exponentially stretching continuous surface with suction," Archives of Mechanics, vol. 53, no. 6, pp. 643-651, 2001.

[38] S. K. Khan and E. Sanjayanand, "Viscoelastic boundary layer flow and heat transfer over an exponential stretching sheet," International Journal of Heat and Mass Transfer, vol. 48, no. 8, pp. 1534-1542, 2005.

[39] M. K. Partha, P. V. S. N. Murthy, and G. P. Rajasekhar, "Effect of viscous dissipation on the mixed convection heat transfer from an exponentially stretching surface," Heat and Mass Transfer, vol. 41, no. 4, pp. 360-366, 2005.

[40] E. Sanjayanand and S. K. Khan, "On heat and mass transfer in a viscoelastic boundary layer flow over an exponentially stretching sheet," International Journal of Thermal Sciences, vol. 45, no. 8, pp. 819-828, 2006.

[41] M. Q. Al-Odat, R. A. Damseh, and T. A. Al-Azab, “Thermal boundary layer on an exponentially stretching continuous surface in the presence of magnetic field effect," International Journal of Applied Mechanics and Engineering, vol. 11, pp. 289299, 2006.

[42] M. Sajid and T. Hayat, "Influence of thermal radiation on the boundary layer flow due to an exponentially stretching sheet," International Communications in Heat and Mass Transfer, vol. 35, no. 3, pp. 347-356, 2008.

[43] B. Bidin and R. Nazar, "Numerical solution of the boundary layer flow over an exponentially stretching sheet with thermal radiation," European Journal of Scientific Research, vol. 33, no. 4, pp. 710-717, 2009.

[44] A. Ishak, "MHD boundary layer flow due to an exponentially stretching sheet with radiation effect," Sains Malaysiana, vol. 40, no. 4, pp. 391-395, 2011.

[45] I. C. Mandal and S. Mukhopadhyay, "Heat transfer analysis for fluid flow over an exponentially stretching porous sheet with surface heat flux in porous medium," Ain Shams Engineering Journal, vol. 4, no. 1, pp. 103-110, 2013.

[46] K. Bhattacharyya, "Boundary layer flow and heat transfer over an exponentially shrinking sheet," Chinese Physics Letters, vol. 28, no. 7, Article ID 074701, 2011.

[47] K. Bhattacharyya and I. Pop, "MHD Boundary layer flow due to an exponentially shrinking sheet," Magnetohydrodynamics, vol. 47, pp. 337-344, 2011.

[48] K. Bhattacharyya and G. C. Layek, "Magnetohydrodynamic boundary layer flow of nanofluid over an exponentially stretching permeable sheet," Physics Research International, vol. 2014, Article ID 592536, 12 pages, 2014. 

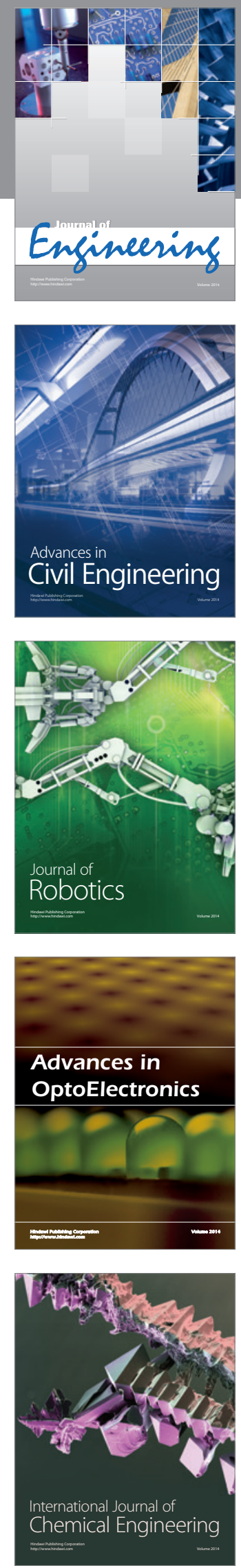

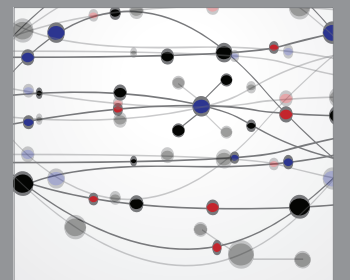

The Scientific World Journal
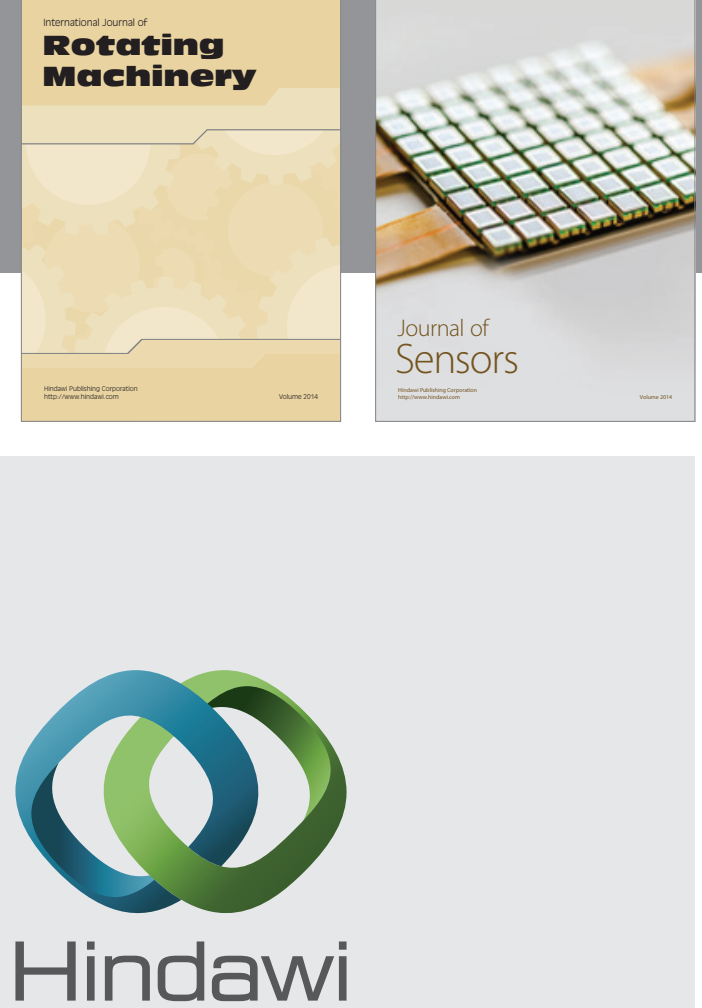

Submit your manuscripts at http://www.hindawi.com
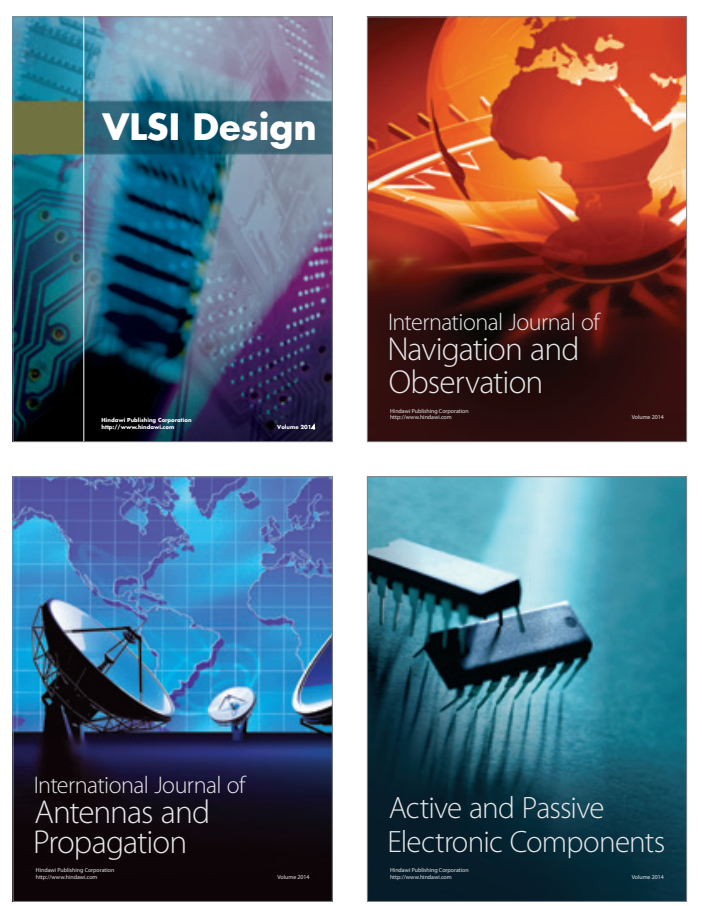
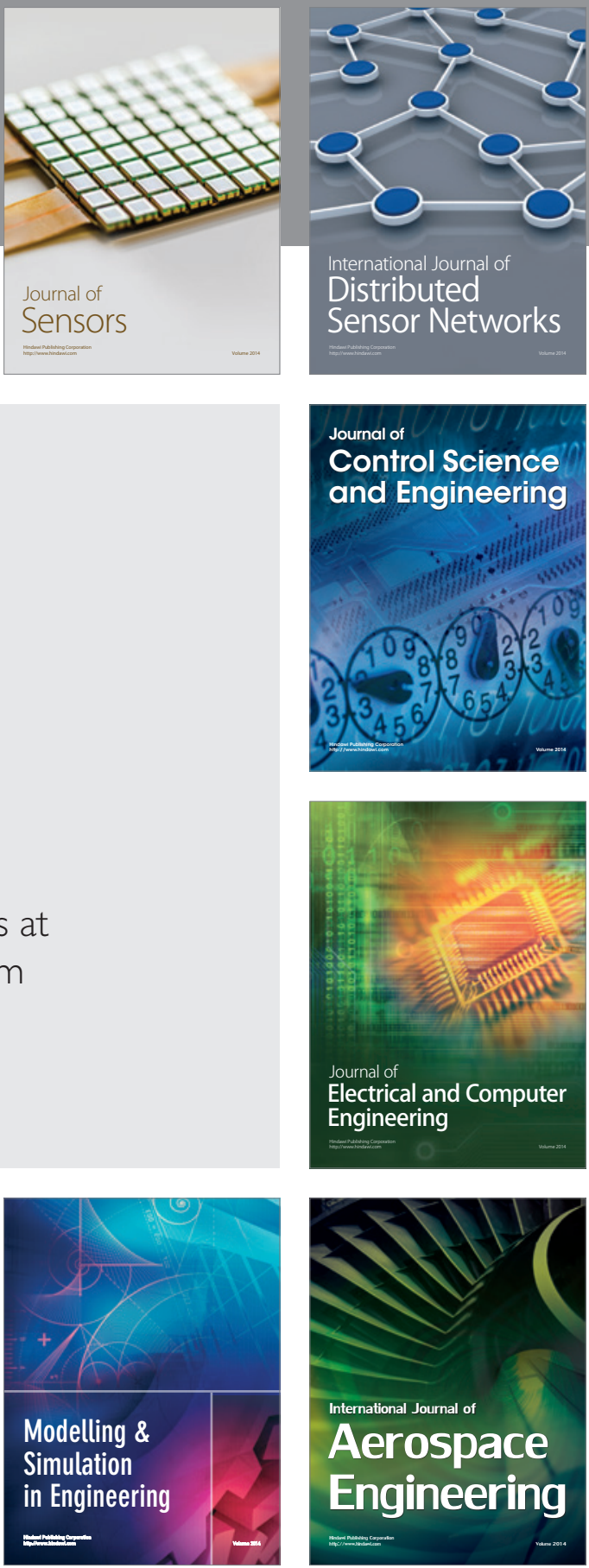

Journal of

Control Science

and Engineering
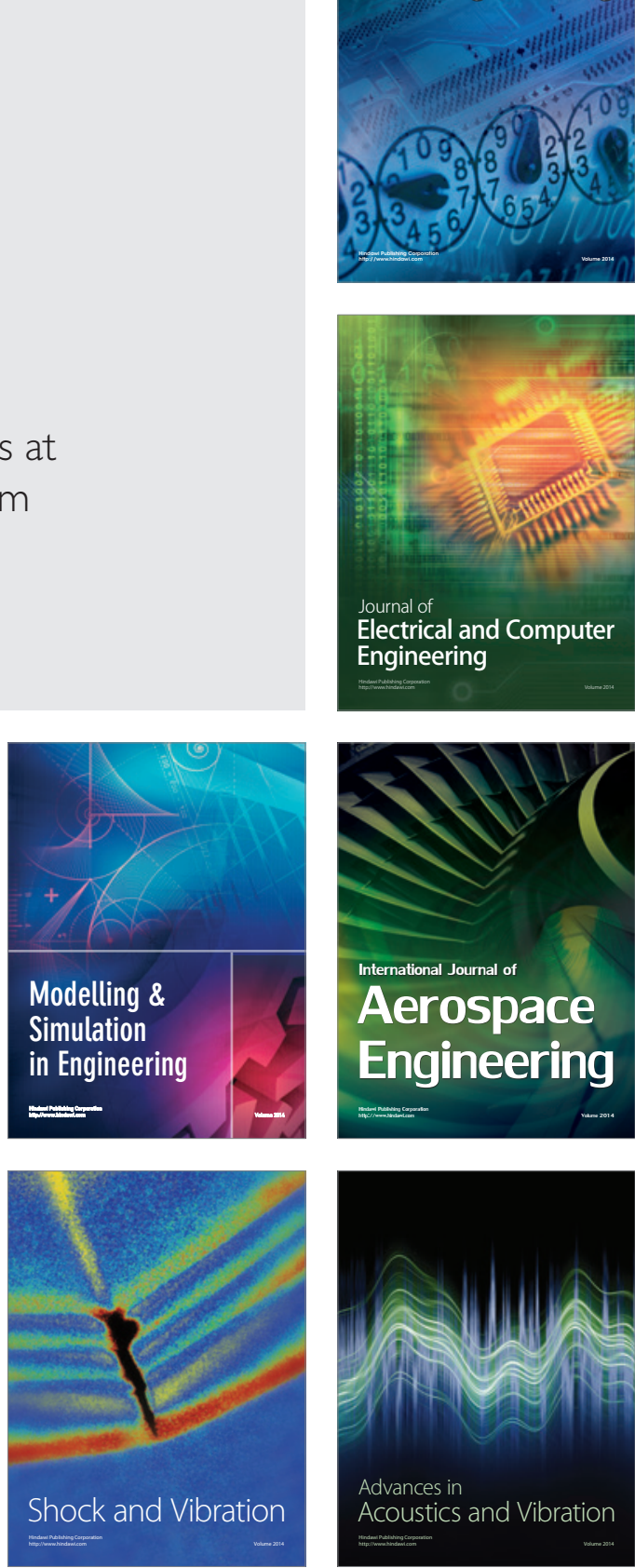